\title{
Review
}

\section{Alzheimer's Disease and Empathic Abilities: The Proposed Role of the Cingulate Cortex}

\author{
Marina Ávila-Villanueva ${ }^{\mathrm{a}}$, Jaime Gómez-Ramírez ${ }^{\mathrm{a}}$, Jesús Ávila ${ }^{\mathrm{b}, \mathrm{c}}$ \\ and Miguel A. Fernández-Blázquez ${ }^{\mathrm{a}, \mathrm{d}, *}$ \\ ${ }^{a}$ Alzheimer Disease Research Unit, CIEN Foundation, Carlos III Institute of Health, Queen Sofía Foundation \\ Alzheimer Center, Madrid, Spain \\ ${ }^{\mathrm{b}}$ Center of Molecular Biology Severo Ochoa (CSIC-UAM), Campus de Cantoblanco, Madrid, Spain \\ ${ }^{\mathrm{c}}$ Network Center for Biomedical Research in Neurodegenerative Diseases (CIBERNED), Madrid, Spain \\ ${ }^{\mathrm{d}}$ Department of Experimental Psychology, Cognitive Processes and Speech Therapy, Complutense University of \\ Madrid (UCM), Campus de Somosaguas, Pozuelo de Alarcón, Madrid, Spain
}

Accepted 25 March 2021

Pre-press 16 April 2021

\begin{abstract}
In recent years there has been increasing interest in examining the role of empathic abilities in Alzheimer's disease (AD). Empathy, the ability to understand and share another person's feelings, implies the existence of emotional and cognitive processes and is a pivotal aspect for success in social interactions. In turn, self-empathy is oriented to one's thoughts and feelings. Decline of empathy and self-empathy can occur during the AD continuum and can be linked to different neuroanatomical pathways in which the cingulate cortex may play a crucial role. Here, we will summarize the involvement of empathic abilities through the AD continuum and further discuss the potential neurocognitive mechanisms that contribute to decline of empathy and self-empathy in AD.
\end{abstract}

Keywords: Aging, Alzheimer's disease, anosognosia, cingulate cortex, empathy

\section{INTRODUCTION}

Alzheimer's disease (AD) is the most prevalent form of neurodegenerative dementia. It is typically characterized by early and progressive episodic memory loss. The progressive neurodegeneration initially involves the hippocampi, the entorhinal, and cingulate cortex, and, subsequently, it spreads to the entire

*Correspondence to: Miguel A. Fernández-Blázquez, Department of Experimental Psychology, Cognitive Processes and Speech Therapy, School of Psychology, Complutense University of Madrid, Campus de Somosaguas, 28223 Pozuelo de Alarcón, Madrid, Spain. Tel.: +34913943117.E-mail: ma.fdez.blazquez@ gmail.com. temporal, parietal, and frontal lobes [1]. Research in $\mathrm{AD}$ has recently focused on examining the concept of empathy. It is a complex and multidimensional construct in relation to the ability to understand and share the emotional and mental states of others [2, $3]$. Empathy plays a pivotal role in social interactions as an enhancer of prosocial behaviors and adaptive social responses to context. Furthermore, empathy correlates positively with the degree of life satisfaction, emotional intelligence and self-esteem [4].

On the other hand, self-empathy can also be distinguished from empathy. Self-empathy is oriented to oneself and, thus its study may help us understand better one's thoughts and feelings. In both cases, 
impairment of empathy and self-empathy can occur during the course of the $\mathrm{AD}$ and can be observed by anatomical inspection in different brain areas. AD patients have been found to show impaired social behavior, theory of mind, empathy, emotion recognition, and inaccurate self-awareness, and, although uncommon as first symptoms, severe behavioral alterations such as disinhibition, social awkwardness, and apathy [5]. Here we will discuss the involvement of empathy and self-empathy through the AD continuum, also providing an in-depth revision of the shared neural pathways by both empathy and self-empathy.

\section{EMPATHY}

Empathy enables individuals to participate in social situations, allowing them to perceive and recognize thoughts, emotions, and behaviors of others. Specifically, the ability to recognize and understand emotions and intentions in others is crucial for maintaining successful social interactions. There is considerable consensus that empathy comprises two main components [3, 6]. First, affective empathy refers to the ability to recognize, understand, and share the affective other's states, emotions, or feelings. Second, cognitive empathy refers to the ability to understand and predict other's beliefs, thoughts, or intentions and may be considered as equivalent to the so-called construct of theory of mind. This conceptualization is supported by the involvement of different neural pathways that underlie the two dimensions of empathy $[6,7]$. Regions underlying the functions of affective empathy are the inferior frontal cortex, inferior parietal lobe, anterior cingulate cortex (ACC), and anterior insula [7-11]. Conversely, cognitive empathy relies on the medial prefrontal cortex, the superior temporal sulcus, the temporo-parietal junction, and the temporal poles [7]. Further evidence in favor of this dissociation have been found in separate EEG event-related potentials associated with affective and cognitive empathy [12]. In any case, it should be noted that the development of empathy must be contextualized in the socio-cultural environment in which an individual grows up. That would explain the premorbid interindividual differences of empathy. Factors such as education, gender, and social engagement have been examined to better understand the role of possible modulators between aging, $\mathrm{AD}$, and empathy. Thus, some studies have reported that characteristics such as higher education, female gender, and successful interpersonal relationships correlate with greater empathic abilities [13-15].

\section{THE ROLE OF EMPATHY IN HEALTHY AGING AND AD CONTINUUM}

There is growing evidence indicating that older age is associated with reduced capacity for empathy $[16,17]$. Research findings suggest that older adults may have deficits in both affective and cognitive empathic dimensions. Aging is associated with deficits on both first- and, more specifically, secondorder theory of mind tasks, which underlies a specific age-related deficit in the ability to infer one's own and other people's thoughts, feelings, and mental states [4]. Likewise, older adults also show decline in affective recognition, particularly for negative facial expressions, with positive emotions relatively preserved [18]. These changes, rather than be due to selective declines in brain regions involved in perceiving specific emotions, seem to be related to the way in which older adults process faces [19].

During aging, there is a decrease in the reported social network sizes $[20,21]$. However, this seems not to be a random decrease since a possible explanation is that older people prioritize positive social interactions over other ones [22]. It has been suggested that such prioritization occurs in normal aging, but this phenomenon would probably not operate in the same way in the very early preclinical stages of AD. Thus, an incipient sign for the development of a later neurodegenerative disorder such as AD could be the presence of subtle changes in social functioning that lead to violation of social conventions, social withdrawn, and isolation [23]. However, it should be noted that those changes could be secondary to the general cognitive decline that accompanies AD [24, 25]. In particular, cognitive empathy has been found to be mediated by executive functions $[26,27]$.

Changes in the ability of recognizing and understanding emotions and mental states in others seem to occur early in the $\mathrm{AD}$ continuum independently on the presence of cognitive deficits $[28,29]$. Since social interaction has beneficial effects on cognitive status and specific domains such as memory [30]; a decrease in the quantity and quality of social contacts may be indicative of a neurodegenerative disorder onset. Indeed, social isolation has been associated with faster progression of cognitive impairment and higher mortality [31]. 
Different types of positive social interactions, especially related to empathy and other personal connections may be involved in the early stages of $\mathrm{AD}$ [8]. Indeed, loss of empathy has been reported in $\mathrm{AD}$, particularly the cognitive component of empathy versus a relatively preservation of the affective component [32]. To confirm this association with the disease, some studies have been carried out with cases of familial Alzheimer's disease (FAD) [33, 34]. The findings of those studies have highlighted the presence of specific early social behavioral changes in carriers of autosomal dominant mutations in $\mathrm{AD}$ [33]. These results have been to some extent confirmed in mouse models that express the human genes containing FAD mutations; thus, it has been proven that these mouse models with cognitive dysfunctions also develop early social disturbances $[9,35,36]$.

Regarding neuroanatomical bases underlying the link between empathy and AD, the ACC seems to play a crucial role as it is involved in the ability to recognize emotions in others [37]. In fact, there is growing evidence pointing out that empathic relationships are not only related to the "mirror system" but also to the ACC [8]. However, active social decision-making

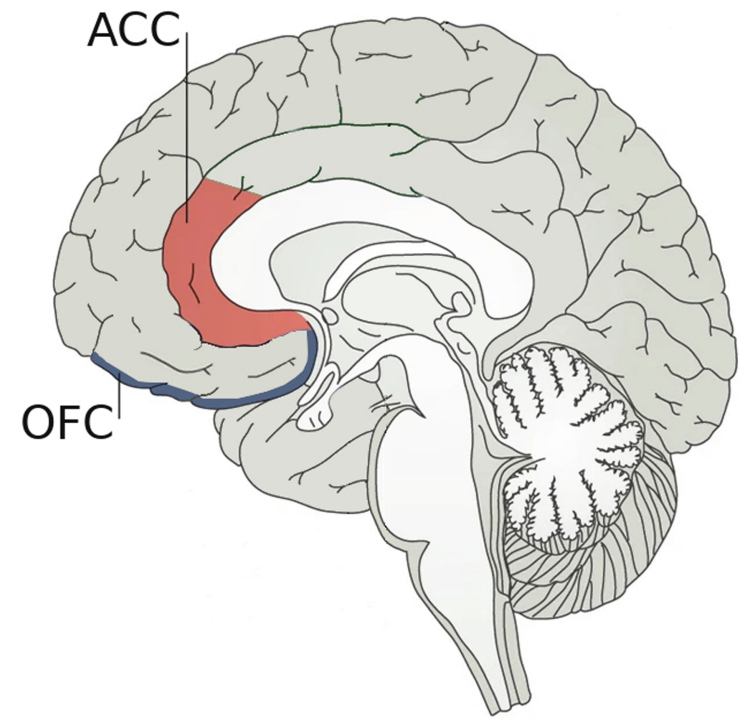

Fig. 1. Neuroanatomical bases underlying social decision-making. Social decision-making, which is crucial to establishing and maintaining successful social relationships, is supported by two pivotal brain regions: 1) the anterior cingulate cortex (ACC) that plays an important role in the ability to recognize emotions by evaluating predictions about the emotional states of others; and 2) the orbital frontal cortex (OFC) that judges the possible choices of behavior. Damage in any of these two areas could affect social cognition. is critical to establishing and maintaining successful social relationships, involving not only the ACC but also the orbital frontal cortex (OFC) as depicted in Fig. 1 [38]. For social decision-making, the ACC would evaluate different predictions about the emotional states of others, while the OFC would judge the value of possible choices of behavior and determine social preferences [10,39]. Hence, damage in any of these areas could affect social cognition. Although more work needs to be done to find a possible mechanism to link changes in ACC to the alterations in social behavior associated with the early stages of $\mathrm{AD}, \mathrm{FAD}$ is already providing important clues. In $\mathrm{FAD}$, amyloid is deposited very early in the precuneus [40], which is a brain structure that interacts with ACC through various cortical connections [41]. It could be argued that a decrease in these interactions could affect the functioning of the ACC and, secondarily, empathy.

\section{THE ROLE OF SELF-EMPATHY IN AD CONTINUUM}

Self-empathy refers to a personal facet of oneself by which one can recognize and become aware of what is going on in one's own mind [42]. As with empathy, there are two dimensions for self-empathy related to the affective and cognitive components of one's inner mind. Most importantly, self-empathy provides a unique framework in which to integrate and compare the events of one's current and past experiences; in this same framework, it is also possible to compare one's own experiences with those of other people.

In the first phases of the $\mathrm{AD}$ continuum a progressive transition takes place between the non-demented asymptomatic stage, in which one continues to live a normal life with appropriate cognitive and social functioning, and the beginning of an incipient subjective cognitive decline plus (SCD-P) phase [43-45]. SCD-P refers to a self-experienced persistent decline in cognitive functioning in comparison with a prior normal status and independent of the objective performance on neuropsychological tests. Self-empathy allows a person to become aware of the first subtle cognitive complaints experienced in the SCD-P phase by comparing one's current cognitive performance with her own premorbid status as well as with the cognitive performance of other people with similar age or condition. 
The most frequent symptom in SCD-P, but not solely, is memory loss. Damage to the connections between entorhinal cortex (EC) and hippocampal areas seems to be at the base of memory complaints $[46,47]$. Structural changes in medial prefrontal cortex and temporo-parietal junction [48] as well as in the medial temporal lobe have also been reported in individuals with SCD-P [49]. In the hippocampus, CA1 is the minimum region essential for the functioning of episodic memory [50-53]. Mainly, connections between EC and CA1 are involved in the acquisition of new memories [54]. Injury to these connections can lead to characteristic memory loss in AD. However, not only individual resilience and compensating factors such as cognitive reserve may help to slow down memory loss [55, 56], but also alternative pathways for connecting the cerebral cortex and CA 1 have been recently identified. It has been described an alternative neural circuitry that could delay the transition from a non-demented stage to a mild cognitive impairment (MCI) [57]. This alternative pathway, that can connect cerebral cortex to CA1 without going through the EC [58], includes posterior cingulate cortex (PCC), mammillary bodies, and hippocampal CA2. In this circuitry the involvement of PCC appears to be different to the early deficits found in ACC [59]; the functional decrease of PCC occurs later in the AD continuum, specifically in the MCI stage when a decreased connectivity between PCC and hippocampus may be evidenced [59].

From the molecular perspective, it has been identified a high proportion of amyloid- $\beta$ peptide $(A \beta)$ and a low concentration of tau in the cingulate cortex $[60,61]$. However, the opposite trend can be observed in the EC, where more abundant tau deposits and a lower proportion of $A \beta$ have been reported [60]. In this sense, it has been postulated that the alternative neural pathway may lose its functionality and, therefore, its ability to compensate, once the PCC is impaired. The damage in this region could occur when the tau deposits of the EC are transported and reach the PCC. Thus, the transport time of tauopathy from EC to PCC could be related to the time of disease progression from the preclinical and prodromal phases to the dementia stage [62].

As the disease progresses and cognitive impairment worsens, self-empathy also deteriorates. Self-empathy is a necessary precondition for selfawareness of one's inner state; both are qualitatively different concepts and can be distinguished [7, 65].
From a phenomenological point of view, impairment in self-empathy causes an impairment in self-awareness. This is what can be observed from late MCI to subsequent stages of $\mathrm{AD}$ dementia, where patients may begin to suffer from self-empathy deficits that immediately affects self-awareness and prevents them from recognizing the changes caused by the cognitive impairment associated with the disease. Self-awareness would include three different components, namely: 1) the recognition of a specific deficit; 2) the emotional response elicited by that deficit; and 3 ) the understanding of the functional impact that the deficit has on daily life [63]. Lack of self-awareness of memory deficits in MCI is important because it is a marker for conversion to $\mathrm{AD}$ [64].

In 1914, Babinski coined the term anosognosia which, in medical settings, means that a patient is unable to perceive his or her own acquired deficits as well as their functional implications in everyday life [66]. More generally, anosognosia is the most extreme loss of self-awareness that affects to the introspective capacity [67] and produces a lack of free will or freedom of choice, leading to a total dependence from others [68-71]. In the field of dementia, anosognosia is a common symptom of later stages of $\mathrm{AD}$; overall, anosognosia is present in $\mathrm{AD}$ patients with an estimated frequency ranging $20-80 \%$ [72-75]. It is commonly related to a metacognitive executive dysfunction [76]; indeed, the executive neural networks show some overlap with those that support empathy and self-empathy [77, 78], so neurodegeneration at these networks can lead to the appearance of anosognosia. In particular, the most consistent correlations between anosognosia and cognitive processes include cognitive flexibility, mental control, problem solving and frontal behaviors such as prehension, utilization, imitation, inertia, and indifference [64].

From a neuroanatomical point of view, anosognosia has been associated with extensive brain damage, mainly affecting the right hemisphere, specifically the inferior parietal lobe and frontal inferior and dorsolateral regions [79]. Specifically, in MCI anosognosia is associated with a reduced gray matter volume of the ACC and of the inferior frontal cortex [64] as well as a reduced PCC functioning and a decreased hippocampal metabolism [80]. In the first phases of $\mathrm{AD}$, the presence of anosognosia is associated with different structures of the medial temporal lobe [81] and a specific disconnection within the medial temporal subsystem of the default mode network $[82,83]$. 
Table 1

Proposed neuroanatomical changes at cingulate cortex in AD continuum and their association with changes in empathic abilities

\begin{tabular}{lcl}
\hline $\begin{array}{l}\text { AD continuum } \\
\text { stage }\end{array}$ & $\begin{array}{c}\text { Cingulate } \\
\text { cortex region }\end{array}$ & $\begin{array}{l}\text { Empathic } \\
\text { abilities }\end{array}$ \\
\hline Early & ACC & $\begin{array}{l}\text { Cognitive empathy and } \\
\text { Emotion recognition } \\
\text { Lelf-empathy, Self-awareness } \\
\text { and Anosognosia }\end{array}$ \\
\hline
\end{tabular}

Proposed correlation between dysfunction at different regions of cingulate cortex and changes in empathic abilities through the AD continuum. ACC, anterior cingulate cortex; PCC, posterior cingulate cortex.

\section{DISCUSSION}

Empathy and self-empathy abilities have been little researched in the field of AD. In general, as the disease progresses, it is possible to find a correlation between changes in both abilities and brain degeneration $[84,85]$. Specifically, it is well-known that through the $\mathrm{AD}$ continuum there is a degeneration of the EC $[46,86]$. This degeneration has two direct and fatal consequences: on the one hand, the connectivity of the hippocampal CA1 is undermined [87] and, on the other hand, the functionality of the PCC is diminished [59, 88]. In this way, connections between the cerebral cortex and the CA1 are impaired, either through the EC or through the PCC, leading to loss of memory [57]. Thus, by looking at the rate of decline of the cingulate cortex and the empathic abilities in the $\mathrm{AD}$ continuum, we can glimpse a link between them (Table 1). Here, we hypothesize that in the early stages of the disease, changes in the ACC would occur and produce a decrease in cognitive empathy and emotion recognition that lead to a decreased in maintaining social relationships; whereas in the later AD stages, changes in PCC would appear and lead to a self-empathy impairment and anosognosia [89].

All the above has practical implications insofar as empathic abilities are an inherent part of the human condition. On the one hand, a subtle impairment of the cognitive empathy, such as that observed in the early preclinical stages of $\mathrm{AD}$, entails socio-behavioral changes that, in turn, reflect changes in personality traits, and lead to more or less apparent limitations in adapting effectively to the social environment [90]. Such limitations would produce a consequent deterioration of social activity either by loss of initiative of the individual himself or by lack of interest of others in relating to a person who does not adjust to social norms. As a vicious circle, social isolation would increase the progression of cognitive impairment [91]. On the other hand, the progressive accumulation of $A \beta$ that typically occurs from late MCI, produces a decline of self-empathy and a consequently loss of awareness of one's own deficits and limitations in daily life [92]. The appearance of anosognosia worsens the prognosis of patients to the extent that they do not perceive the need to undergo pharmacological and non-pharmacological therapeutic interventions; in addition, anosognosia also has a negative impact on the main caregivers of these patients, increasing their levels of anxiety and stress and diminishing their quality of life [69].

In sum, a better understanding of the changes in empathy and self-empathy associated with $\mathrm{AD}$, as well as its neuroanatomical basis, may help identify early individuals at risk of progression, improve and personalize interventions on patients for the purpose of modifying the course of the disease, and ultimately improve the quality of life of patients and their caregivers.

\section{ACKNOWLEDGMENTS}

We wish to thank warmly to the Carlos III Institute of Health and Queen Sofia Foundation for its sponsorship and continuous support. This study was funded by the Spanish Ministry of Science, Innovation and Universities -State Research Agency- under the Grant RTI2018-098762-A-C32 by the European Regional Development Fund. Complimentary, it was supported by the multidisciplinary Research Program of the Fundación General de la Universidad de Salamanca (FGUSAL) in the framework of the Centro Internacional sobre el Envejecimiento (CENIE) co-funded by the Interreg V-A Programme, Spain - Portugal, (POCTEP), 2014-2020 under the Grant 0348_CIE_6_E by the European Regional Development Fund.

\section{CONFLICT OF INTEREST}

The authors have no conflict of interest to report.

\section{REFERENCES}

[1] Frisoni GB, Fox NC, Jack CR, Scheltens P, Thompson PM (2010) The clinical use of structural MRI in Alzheimer disease. Nat Rev Neurol 6, 67-77.

[2] Baron-Cohen S, Wheelwright S (2004) The empathy quotient: An investigation of adults with asperger syndrome or high functioning autism, and normal sex differences. $J$ Autism Dev Disord 34, 163-175. 
[3] Decety J, Jackson PL (2004) The functional architecture of human empathy. Behav Cogn Neurosci Rev 3, 71-100.

[4] Yang T, Banissy MJ (2016) Empathy and aging: Mechanisms of empathy throughout adulthood. In The Neurobiology and Psychology of Empathy, Watt DF, Panksepp J, eds. Nova Science Publishers, Inc, New York, NY, pp. 211-226.

[5] Trojsi F, Christidi F, Migliaccio R, Santamaría-García H, Santangelo G (2018) Behavioural and cognitive changes in neurodegenerative diseases and brain injury. Behav Neurol 2018, 4935915.

[6] Shamay-Tsoory SG (2011) The neural bases for empathy. Neuroscientist 17, 18-24.

[7] Bernhardt BC, Singer T (2012) The neural basis of empathy. Annu Rev Neurosci 35, 1-23.

[8] De Waal FBM, Preston SD (2017) Mammalian empathy: Behavioural manifestations and neural basis. Nat Rev Neurosci 18, 498-509.

[9] Schneider F, Baldauf K, Wetzel W, Reymann KG (2014) Behavioral and EEG changes in male 5xFAD mice. Physiol Behav 135, 25-33.

[10] Kennerley SW, Behrens TEJ, Wallis JD (2011) Double dissociation of value computations in orbitofrontal and anterior cingulate neurons. Nat Neurosci 14, 1581-1589.

[11] Akam T, Rodrigues-Vaz I, Marcelo I, Zhang X, Pereira M, Oliveira RF, Dayan P, Costa RM (2021) The anterior cingulate cortex predicts future states to mediate model-based action selection. Neuron 109, 149-163.e7.

[12] Sessa P, Meconi F, Han S (2014) Double dissociation of neural responses supporting perceptual and cognitive components of social cognition: Evidence from processing of others' pain. Sci Rep 4, 7424.

[13] Grühn D, Rebucal K, Diehl M, Lumley M, Labouvie-Vief G (2008) Empathy across the adult lifespan: Longitudinal and experience-sampling findings. Emotion 8, 753-765.

[14] O'Brien E, Konrath SH, Grühn D, Hagen AL (2013) Empathic concern and perspective taking: Linear and quadratic effects of age across the adult life span. J Gerontol Ser B Psychol Sci Soc Sci 68, 168-175.

[15] Schieman S, Van Gundy K (2000) The personal and social links between age and self-reported empathy. Soc Psychol $Q 63,152-174$.

[16] Beadle JN, De La Vega CE (2019) Impact of aging on empathy: Review of psychological and neural mechanisms. Front Psychiatry 10, 331.

[17] Bailey PE, Henry JD, Von Hippel W (2008) Empathy and social functioning in late adulthood. Aging Ment Heal 12, 499-503.

[18] Keightley ML, Winocur G, Burianova H, Hongwanishkul D, Grady CL (2006) Age effects on social cognition: Faces tell a different story. Psychol Aging 21, 558-572.

[19] Mather M (2016) The affective neuroscience of aging. Annu Rev Psychol 67, 213-238.

[20] Wrzus C, Hänel M, Wagner J, Neyer FJ (2013) Social network changes and life events across the life span: A meta-analysis. Psychol Bull 139, 53-80.

[21] Bruine de Bruin W, Parker AM, Strough JN (2020) Age differences in reported social networks and well-being. Psychol Aging 35, 159-168.

[22] D'Agostino AE, Kattan D, Canli T (2019) An fMRI study of loneliness in younger and older adults. Soc Neurosci 14, 136-148.

[23] Rotenberg-Shpigelman S, Erez ABH, Nahaloni I, Maeir A (2012) Neurofunctional treatment targeting participation among chronic stroke survivors: A pilot randomised controlled study. Neuropsychol Rehabil 22, 532-549.

[24] Dodich A, Cerami C, Crespi C, Canessa N, Lettieri G, Iannaccone S, Marcone A, Cappa SF, Cacioppo JT (2016) Differential impairment of cognitive and affective mentalizing abilities in neurodegenerative dementias: Evidence from behavioral variant of frontotemporal dementia, Alzheimer's disease, and mild cognitive impairment. J Alzheimers Dis 50, 1011-1022.

[25] Kemp J, Després O, Sellal F, Dufour A (2012) Theory of Mind in normal ageing and neurodegenerative pathologies. Ageing Res Rev 11, 199-219.

[26] Maylor EA, Moulson JM, Muncer AM, Taylor LA (2002) Does performance on theory of mind tasks decline in old age? Br J Psychol 93, 465-485.

[27] Charlton RA, Barrick TR, Markus HS, Morris RG (2009) Theory of Mind associations with other cognitive functions and brain imaging in normal aging. Psychol Aging 24, 338348.

[28] MacRae H (2011) Self and other: The importance of social interaction and social relationships in shaping the experience of early-stage Alzheimer's disease. J Aging Stud 25, 445-456.

[29] Hsiao YH, Chang CH, Gean PW (2018) Impact of social relationships on Alzheimer's memory impairment: Mechanistic studies. J Biomed Sci 25.

[30] Kelly ME, Duff H, Kelly S, McHugh Power JE, Brennan S, Lawlor BA, Loughrey DG (2017) The impact of social activities, social networks, social support and social relationships on the cognitive functioning of healthy older adults: A systematic review. Syst Rev 6, 259.

[31] Friedler B, Crapser J, McCullough L (2015) One is the deadliest number: The detrimental effects of social isolation on cerebrovascular diseases and cognition. Acta Neuropathol 129, 493-509.

[32] Dermody N, Wong S, Ahmed R, Piguet O, Hodges JR, Irish M (2016) Uncovering the neural bases of cognitive and affective empathy deficits in Alzheimer's disease and the behavioral-variant of frontotemporal dementia. $J$ Alzheimers Dis 53, 801-816.

[33] Ringman JM, Liang LJ, Zhou Y, Vangala S, Teng E, Kremen S, Wharton D, Goate A, Marcus DS, Farlow M, Ghetti B, McDade E, Masters CL, Mayeux RP, Rossor M, Salloway S, Schofield PR, Cummings JL, Buckles V, Bateman R, Morris JC (2015) Early behavioural changes in familial Alzheimer's disease in the Dominantly Inherited Alzheimer Network. Brain 138, 1036-1045.

[34] Ng KP, Pascoal TA, Mathotaarachchi S, Chan YH, Jiang L, Therriault J, Benedet AL, Shin M, Kandiah N, Greenwood CMT, Rosa-Neto P, Gauthier S (2021) Neuropsychiatric symptoms are early indicators of an upcoming metabolic decline in Alzheimer's disease. Transl Neurodegener $\mathbf{1 0}, 1$.

[35] Kong V, Devenyi GA, Gallino D, Ayranci G, Germann J, Rollins C, Chakravarty MM (2018) Early-in-life neuroanatomical and behavioural trajectories in a triple transgenic model of Alzheimer's disease. Brain Struct Funct 223, 3365-3382.

[36] Kosel F, Torres Munoz P, Yang JR, Wong AA, Franklin TB (2019) Age-related changes in social behaviours in the 5xFAD mouse model of Alzheimer's disease. Behav Brain Res 362, 160-172.

[37] Schneider KN, Sciarillo XA, Nudelman JL, Cheer JF, Roesch MR (2020) Anterior cingulate cortex signals atten- 
tion in a social paradigm that manipulates reward and shock. Curr Biol 30, 3724-3735.e2.

[38] Besnard J, Le Gall D, Chauviré V, Aubin G, Etcharry-Bouyx F, Allain P (2017) Discrepancy between social and nonsocial decision-making under uncertainty following prefrontal lobe damage: The impact of an interactionist approach. Soc Neurosci 12, 430-447.

[39] Seo H, Lee D (2012) Neural basis of learning and preference during social decision-making. Curr Opin Neurobiol 22, 990-995.

[40] Bateman RJ, Xiong C, Benzinger TLS, Fagan AM, Goate A, Fox NC, Marcus DS, Cairns NJ, Xie X, Blazey TM, Holtzman DM, Santacruz A, Buckles V, Oliver A, Moulder K, Aisen PS, Ghetti B, Klunk WE, McDade E, Martins RN, Masters CL, Mayeux R, Ringman JM, Rossor MN, Schofield PR, Sperling RA, Salloway S, Morris JC (2012) Clinical and biomarker changes in dominantly inherited Alzheimer's disease. N Engl J Med 367, 795-804.

[41] Cavanna AE, Trimble MR (2006) The precuneus: A review of its functional anatomy and behavioural correlates. Brain 129, 564-583.

[42] Sherman N (2014) Recovering lost goodness: Shame, guilt, and self-empathy. Psychoanal Psychol 31, 217-235.

[43] Jessen F, Amariglio RE, Van Boxtel M, Breteler M, Ceccaldi M, Chételat G, Dubois B, Dufouil C, Ellis KA, Van Der Flier WM, Glodzik L, Van Harten AC, De Leon MJ, McHugh P, Mielke MM, Molinuevo JL, Mosconi L, Osorio RS, Perrotin A, Petersen RC, Rabin LA, Rami L, Reisberg B, Rentz DM, Sachdev PS, De La Sayette V, Saykin AJ, Scheltens P, Shulman MB, Slavin MJ, Sperling RA, Stewart R, Uspenskaya O, Vellas B, Visser PJ, Wagner M (2014) A conceptual framework for research on subjective cognitive decline in preclinical Alzheimer's disease. Alzheimers Dement 10, 844-852.

[44] Fernández-Blázquez MA, Ávila-Villanueva M, Maestú F, Medina M (2016) Specific features of subjective cognitive decline predict faster conversion to mild cognitive impairment. J Alzheimers Dis 52, 271-281.

[45] Ávila-Villanueva M, Fernández-Blázquez MA (2017) Subjective cognitive decline as a preclinical marker for Alzheimer's disease: The challenge of stability over time. Front Aging Neurosci 9, 377.

[46] Gómez-Isla T, Price JL, McKeel DWJ, Morris JC, Growdon JH, Hyman BT (1996) Profound loss of layer II entorhinal cortex neurons occurs in very mild Alzheimer's disease. $J$ Neurosci 16, 4491-4500.

[47] Burggren A, Brown J (2014) Imaging markers of structural and functional brain changes that precede cognitive symptoms in risk for Alzheimer's disease. Brain Imaging Behav 8, 251-261.

[48] Liang L, Zhao L, Wei Y, Mai W, Duan G, Su J, Nong X, Yu B, Li C, Mo X, Wilson G, Deng D, Kong J (2020) Structural and functional hippocampal changes in subjective cognitive decline from the community. Front Aging Neurosci 12, 64.

[49] deToledo-Morrell L, Stoub TR, Wang C (2007) Hippocampal atrophy and disconnection in incipient and mild Alzheimer's disease. Prog Brain Res 163, 741-753.

[50] Zola-Morgan S, Squire LR, Amaral DG (1986) Human amnesia and the medial temporal region: Enduring memory impairment following a bilateral lesion limited to field CA1 of the hippocampus. J Neurosci 6, 2950-2967.

[51] Volpe BT, Davis HP, Towle A, Dunlap WP (1992) Loss of hippocampal CA1 pyramidal neurons correlates with memory impairment in rats with ischemic or neurotoxin lesions. Behav Neurosci 106, 457-464.
[52] Tsien JZ, Huerta PT, Tonegawa S (1996) The essential role of hippocampal CA1 NMDA receptor-dependent synaptic plasticity in spatial memory. Cell 87, 1327-1338.

[53] Bueters T, von Euler M, Bendel O, von Euler G (2008) Degeneration of newly formed CA1 neurons following global ischemia in the rat. Exp Neurol 209, 114-124.

[54] Kempermann G, Song H, Gage FH (2015) Neurogenesis in the adult hippocampus. Cold Spring Harb Perspect Biol 7, a018812.

[55] Stern Y (2002) What is cognitive reserve? Theory and research application of the reserve concept. J Int Neuropsychol Soc 8, 448-460.

[56] Stern Y (2006) Cognitive reserve and Alzheimer disease. Alzheimer Dis Assoc Disord 20, 112-117.

[57] Avila J, Perry G, Strange BA, Hernandez F (2015) Alternative neural circuitry that might be impaired in the development of Alzheimer disease. Front Neurosci 9, 145.

[58] Elman JA, Oh H, Madison CM, Baker SL, Vogel JW, Marks SM, Crowley S, O’Neil JP, Jagust WJ (2014) Neural compensation in older people with brain amyloid- $\beta$ deposition. Nat Neurosci 17, 1316-1318.

[59] Zhou Y, Dougherty JH, Hubner KF, Bai B, Cannon RL, Hutson RK (2008) Abnormal connectivity in the posterior cingulate and hippocampus in early Alzheimer's disease and mild cognitive impairment. Alzheimers Dement 4, 265-270.

[60] Shukla C, Bridges LR (1999) Regional distribution of tau, $\beta$ amyloid and amyloid precursor protein in the Alzheimer's brain: A quantitative immunolabelling study. Neuroreport 10, 3785-3789.

[61] Chen XQ, Mobley WC (2019) Alzheimer disease pathogenesis: Insights from molecular and cellular biology studies of oligomeric A $\beta$ and tau species. Front Neurosci 13, 659.

[62] Yassa MA (2014) Ground zero in Alzheimer's disease. Nat Neurosci 17, 146-147.

[63] Clare L (2004) The construction of awareness in early-stage Alzheimer's disease: A review of concepts and models. $\mathrm{Br}$ J Clin Psychol 43, 155-175.

[64] Spalletta G, Piras F, Piras F, Sancesario G, Iorio M, Fratangeli C, Cacciari C, Caltagirone C, Orfei MD (2014) Neuroanatomical correlates of awareness of illness in patients with amnestic mild cognitive impairment who will or will not convert to Alzheimer's disease. Cortex 61, 183195.

[65] Thompson E (2001) Empathy and consciousness. J Conscious Stud 8, 1-32.

[66] Langer KG, Levine DN (2014) Babinski, J. (1914). Contribution to the study of the mental disorders in hemiplegia of organic cerebral origin (anosognosia). Translated by K.G. Langer \& D.N. levine. Translated from the original Contribution ál'Étude des troubles mentaux dans l'hémiplégie organique cérébrale (Anosognosie). Cortex 61, 5-8.

[67] Sunderaraman P, Cosentino S (2017) Integrating the constructs of anosognosia and metacognition: A review of recent findings in dementia. Curr Neurol Neurosci Rep 17, 27.

[68] Vithoulkas G, Muresanu DF (2014) Conscience and consciousness: A definition. J Med Life 7, 104-108.

[69] Turró-Garriga O, Garre-Olmo J, Reñé-Ramírez R, CalvóPerxas L, Gascón-Bayarri J, Conde-Sala J-L (2016) Consequences of anosognosia on the cost of caregivers' care in Alzheimer's Disease. J Alzheimers Dis 54, 1551-1560.

[70] Guerrier L, Le Men J, Gane A, Planton M, Salabert A-S, Payoux P, Dumas H, Bonneville F, Péran P, Pariente J (2018) Involvement of the cingulate cortex in anosognosia: A multi- 
modal neuroimaging study in Alzheimer's disease patients. $J$ Alzheimers Dis 65, 443-453.

[71] Arroyo-Anlló EM, Bouston AT, Fargeau M-N, Orgaz Baz B, Gil R (2017) Self-consciousness deficits in Alzheimer's disease and frontotemporal dementia. J Alzheimers Dis $\mathbf{5 5}$, 1437-1443.

[72] Ruijter NS, Schoonbrood AMG, Twillert B, Hoff EI (2020) Anosognosia in dementia: A review of current assessment instruments. Alzheimers Dement (Amst) 12, e12079.

[73] Tagai K, Nagata T, Shinagawa S, Shigeta M (2020) Anosognosia in patients with Alzheimer's disease: Current perspectives. Psychogeriatrics 20, 345-352.

[74] Starkstein SE (2014) Anosognosia in Alzheimer's disease: Diagnosis, frequency, mechanism and clinical correlates. Cortex 61, 64-73.

[75] Castrillo Sanz A, Andrés Calvo M, Repiso Gento I, Izquierdo Delgado E, Gutierrez Ríos R, Rodríguez Herrero R, Rodríguez Sanz F, Tola-Arribas MA (2016) Anosognosia en la enfermedad de Alzheimer: Prevalencia, factores asociados e influencia en la evolución de la enfermedad. Neurologia 31, 296-304.

[76] Amanzio M, Bartoli M, Cipriani GE, Palermo S (2020) Executive dysfunction and reduced self-awareness in patients with neurological disorders. A mini-review. Front Psychol 11, 1697.

[77] Hynes CA, Baird AA, Grafton ST (2006) Differential role of the orbital frontal lobe in emotional versus cognitive perspective-taking. Neuropsychologia 44, 374-383.

[78] Shamay-Tsoory SG, Tibi-Elhanany Y, Aharon-Peretz J (2006) The ventromedial prefrontal cortex is involved in understanding affective but not cognitive theory of mind stories. Soc Neurosci 1, 149-166.

[79] Gainotti G (2018) Anosognosia in degenerative brain diseases: The role of the right hemisphere and of its dominance for emotions. Brain Cogn 127, 13-22.

[80] Vannini P, Hanseeuw B, Munro CE, Amariglio RE, Marshall GA, Rentz DM, Pascual-Leone A, Johnson KA, Sperling RA (2017) Hippocampal hypometabolism in older adults with memory complaints and increased amyloid burden. Neurology 88, 1759-1767.

[81] Chavoix C, Insausti R (2017) Self-awareness and the medial temporal lobe in neurodegenerative diseases. $\mathrm{Neu}$ rosci Biobehav Rev 78, 1-12.
[82] Antoine N, Bahri MA, Bastin C, Collette F, Phillips C, Balteau E, Genon S, Salmon E (2019) Anosognosia and default mode subnetwork dysfunction in Alzheimer's disease. Hum Brain Mapp 40, 5330-5340.

[83] Avila J, Perry G (2021) A multilevel view of the development of Alzheimer's disease. Neuroscience 457, 283-293.

[84] Demichelis OP, Coundouris SP, Grainger SA, Henry JD (2020) Empathy and theory of mind in Alzheimer's disease: A meta-analysis. J Int Neuropsychol Soc 26, 963-977.

[85] Fischer A, Landeira-Fernandez J, Sollero De Campos F, Mograbi DC (2019) Empathy in Alzheimer's disease: Review of findings and proposed model. J Alzheimers Dis 69, 921-933.

[86] Killiany RJ, Hyman BT, Gomez-Isla T, Moss MB, Kikinis R, Jolesz F, Tanzi R, Jones K, Albert MS (2002) MRI measures of entorhinal cortex vs hippocampus in preclinical AD. Neurology 58, 1188-1196.

[87] Masurkar A V (2018) Towards a circuit-level understanding of hippocampal CA1 dysfunction in Alzheimer's disease across anatomical axes. J Alzheimers Dis Parkinsonism 8, 412.

[88] Lee PL, Chou KH, Chung CP, Lai TH, Zhou JH, Wang PN, Lin CP (2020) Posterior cingulate cortex network predicts Alzheimer's disease progression. Front Aging Neurosci 12, 608667.

[89] Hallam B, Chan J, Gonzalez Costafreda S, Bhome R, Huntley J (2020) What are the neural correlates of meta-cognition and anosognosia in Alzheimer's disease? A systematic review. Neurobiol Aging 94, 250-264.

[90] Terracciano A, An Y, Sutin AR, Thambisetty M, Resnick SM (2017) Personality change in the preclinical phase of Alzheimer disease. JAMA Psychiatry 74, 1259-1265.

[91] Lara E, Caballero FF, Rico-Uribe LA, Olaya B, Haro JM, Ayuso-Mateos JL, Miret M (2019) Are loneliness and social isolation associated with cognitive decline? Int $J$ Geriatr Psychiatry 34, 1613-1622.

[92] Hanseeuw BJ, Scott MR, Sikkes SAM, Properzi M, Gatchel JR, Salmon E, Marshall GA, Vannini P (2020) Evolution of anosognosia in Alzheimer's disease and its relationship to amyloid. Ann Neurol 87, 267-280. 